\title{
Correction: miR-29a contributes to breast cancer cells epithelial-mesenchymal transition, migration, and invasion via downregulating histone H4K20 trimethylation through directly targeting SUV420H2
}

You Wu' ${ }^{1}$, Wanyue Shi', Tingting Tang ${ }^{1}$, Yidong Wang ${ }^{1}$, Xin Yin ${ }^{1}$, Yanlin Chen', Yanfeng Zhang ${ }^{1}$, Yun Xing ${ }^{1}$, Yumeng Shen ${ }^{1}$, Tiansong Xia ${ }^{2}$, Changying Guo ${ }^{1}$, Yi Pan ${ }^{1}$ and Liang Jin ${ }^{1}$

\section{Correction to: Cell Death and Disease https://doi.org/10.1038/s41419-019-1437-0, published online 21 February 2019.}

Since online publication of this article, the authors noticed that there was an error in the images used to compile Fig. 4d. The corrected image is provided below. The authors apologise for any inconvenience caused.

Published online: 12 November 2019

\footnotetext{
Correspondence: Yi Pan (panyi@cpu.edu.cn) or Liang Jin (ljstemcell@cpu.edu.cn) 'State Key Laboratory of Natural Medicines, Jiangsu Key Laboratory of Druggability of Biopharmaceuticals, School of life Science and Technology, China Pharmaceutical University, 24 Tongjiaxiang, Nanjing, Jiangsu province, China

${ }^{2}$ Department of Breast Surgery, Breast Disease Center of Jiangsu Province, First Affiliated Hospital of Nanjing Medical University, 300 Guangzhou Road, Nanjing, Jiangsu province, China

These authors contributed equally: You Wu, Wanyue Shi, Tingting Tang
}

(c) (i) Open Access This article is licensed under a Creative Commons Attribution 4.0 International License, which permits use, sharing, adaptation, distribution and reproduction in any medium or format, as long as you give appropriate credit to the original author(s) and the source, provide a link to the Creative Commons license, and indicate if changes were made. The images or other third party material in this article are included in the article's Creative Commons license, unless indicated otherwise in a credit line to the material. If material is not included in the article's Creative Commons license and your intended use is not permitted by statutory regulation or exceeds the permitted use, you will need to obtain permission directly from the copyright holder. To view a copy of this license, visit http://creativecommons.org/licenses/by/4.0/. 


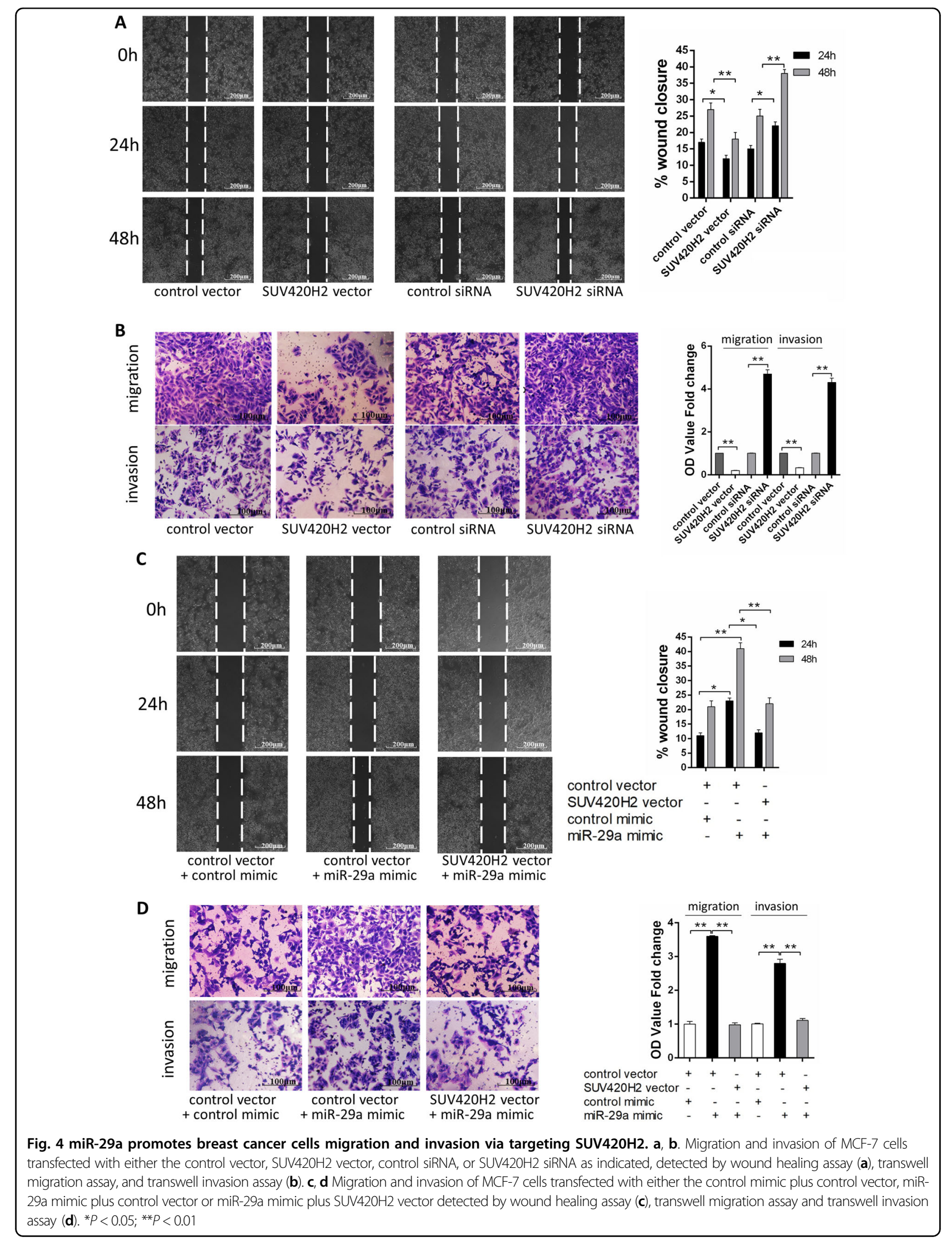

